\title{
ENGENHARIA AMBIENTAL NA INDÚSTRIA \\ ANÁLISE QUALITATIVA DE RESÍDUOS SÓLIDOS EM UMA INDÚSTRIA DE AUTOMAÇÃO AGROINDUSTRIAL
}

Paula Paiva Hofmeister - paula_hof@ hotmail.com

Universidade Federal de Pelotas.

Pamela Lais Cabral Silva - pamela_lais@ hotmail.com

Universidade Federal de Pelotas

Mateus Torres Nazari - nazari.eas@gmail.com

Universidade Federal de Pelotas.

Hartur Xavier - harturxavier93@gmail.com

Universidade Federal de Pelotas.

Gustavo Amaro Bittencourt - gustavobittencourt32@gmail.com

Universidade Federal de Pelotas.

Andréa Souza Castro - andreascastro@gmail.com

Universidade Federal de Pelotas.

Érico Kunde Corrêa - ericokundecorrea@yahoo.com.br

Universidade Federal de Pelotas.

Luciara Bilhalva Corrêa - luciarabc@gmail.com

Universidade Federal de Pelotas.

Resumo: Os resíduos sólidos produzidos no processo produtivo na indústria de automação apresenta grande diversidade de constituintes, classificados como perigosos ou não perigosos. Para um melhor entendimento do processo de gestão desse tipo de resíduo, foi realizado um estudo de caso qualitativo através da observação in loco em uma indústria de automação agroindustrial do Município de Pelotas/RS. Este trabalho buscou entender todo processo produtivo da empresa, onde foram analisadas as matérias primas utilizadas, a forma de tratamento que recebem, o produto final e, por consequência, os resíduos sólidos gerados ao longo do processo. Com isso, foi possível verificar que os RS não são gerenciados corretamente pela empresa, o que está atrelado à falta de informação dos funcionários e colaboradores da empresa que acabam contaminando resíduos que não seriam perigosos através da segregação inadequada, assim como pela forma de tratamento que os resíduos recebem dentro indústria e o descarte em locais inapropriados. À vista de uma legislação cada vez mais rígida, torna-se fundamental uma gestão de RS efetiva e consciente, a fim de se destinar ou dispor adequadamente esse resíduos de modo a não prejudicar e comprometer a saúde pública e o meio ambiente. 
Palavras-chave: Resíduos Sólidos, Resíduos industriais, Indústria de automação.

\section{INTRODUÇÃO E OBJETIVOS}

\section{Segundo a Política Nacional de Resíduos Sólidos (PNRS), os resíduos sólidos definem-se como:

\begin{abstract}
Material, substância, objeto ou bem descartado resultante de atividades humanas em sociedade, cuja destinação final se procede, se propõe proceder ou se está obrigado a proceder, nos estados sólido ou semissólido, bem como gases contidos em recipientes e líquidos cujas particularidades tornem inviável o seu lançamento na rede pública de esgotos ou em corpos d'água, ou exijam para isso soluções técnica ou economicamente inviáveis em face da melhor tecnologia disponível (BRASIL, 2010).
\end{abstract}

Conforme a ABNT NBR 10004 (2004), os resíduos podem ser categorizados em relação a sua periculosidade, classificando-se em: Classe I - Perigosos; Classe II - Não perigosos, esse último é dividido em dois subgrupos: IIA - Não inertes e IIB - Inertes. Ainda de acordo com essa Normativa, a classificação de resíduos envolve a identificação do processo ou atividade que lhes deu origem, de seus constituintes e características e a comparação destes constituintes com listagens de resíduos e substâncias cujo impacto à saúde e ao meio ambiente é conhecido. Abaixo é apresentada a descrição de cada classe segundo essa Normativa:

- Resíduos de Classe I: todo e qualquer resíduo que possuam características físicoquímicas ou infectocontagiosas que apresentam riscos ao meio ambiente e/ou à saúde pública. Estes resíduos devem possuir, pelo menos, uma das seguintes propriedades: inflamabilidade, corrosividade, reatividade, toxicidade e patogenicidade;

- Resíduos de Classe II: aqueles que não são classificados como resíduos de Classe I;

- Classe II A: aqueles resíduos que apresentam solubilidade, biodegradabilidade ou combustibilidade;

- Resíduos de Classe IIB: são resíduos que, quando submetidos a um contato estático ou dinâmico com a água, não tenham seus componentes solubilizados a concentrações superiores as permitidas.

A Revolução Industrial é considerada o marco inicial para as preocupações envolvendo o crescimento nas taxas de resíduos sólidos, uma vez que as indústrias de grande porte entraram em operação, máquinas começaram a ser utilizadas, possibilitando, assim, a produção de bens de consumo em alta escala (CORRÊA \& CORRÊA, 2012). É consensual que o aumento na produção acarreta numa maior geração de resíduos. No Brasil, essa crescente geração vem sendo acompanhada de avanços nas políticas públicas, através de indícios de melhorias nos sistemas de gestão das cidades, instituições públicas e privadas (BRASIL, 2012).

As agroindústrias brasileiras surgiram em 1950 como indústrias rurais movidas através de engenhos a vapor e usinas sistemáticas de moagem. Com o regime militar da década de 70 , houve uma expansão e modernização desse setor. A conhecida "agricultura moderna" ocorreu através de contratos de exportação e grande injeção de capital nas agroindústrias. Para acompanhar o desenvolvimento da agroindústria, as empresas de automação surgiram com o desafio de desenvolver máquinas que aumentem a eficiência dos processos nas indústrias. Atualmente, a demanda é crescente e exigente, sendo necessário o desenvolvimento de 

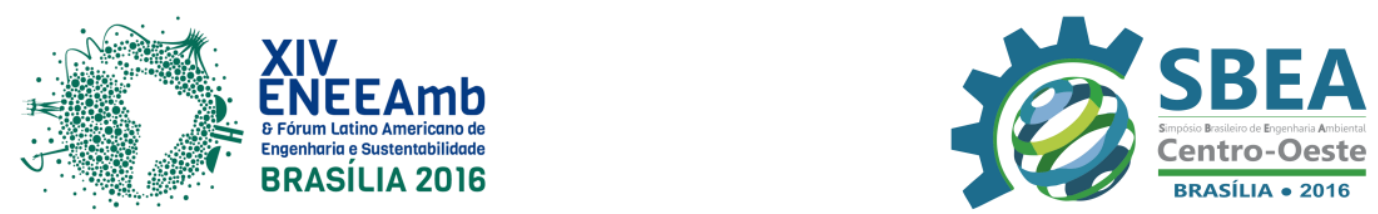

máquinas cada vez mais modernas. Com isso, a automação ganha espaço, tornando-se essencial para empresas de grande porte (HEREDIA, 2010).

A PNRSatribui aos geradores a responsabilidade pela destinação adequada de seus resíduos (BRASIL, 2010). De acordo com Pereira (2008), uma empresa ambientalmente responsável deve minimizar os impactos negativos oriundos de suas atividades, onde a gestão adequada dos resíduos provenientes da cadeia produtiva se apresenta como uma das formas de se alcançar esse objetivo. Desta forma, o plano de gerenciamento de resíduos têm se tornado indispensável às indústrias, seja com a finalidade de cumprir a legislação ou para a obtenção de certificações ambientais.

À vista disso, este estudo objetiva identificar os pontos de geração e qualificar os resíduos gerados de uma indústria de automação para, posteriormente, propor medidas para aumentar a eficiência da gestão de resíduos da empresa. Assim, esse trabalho teve como principais objetivos: a) determinar qualitativamente todos os resíduos gerados;b) identificar os principais pontos de geração; c) conhecer as medidas adotadas pela empresa na gestão de seus resíduos.

\section{METODOLOGIA}

O estudo foi realizado em uma empresa de automação agroindustrial localizada no extremo sul do Rio Grande do Sul, Brasil. Essa empresa dedica-se a produzir equipamentos de automação para o setor agroindustrial que aumentem a eficiência dos processos (maximizando a produção com o menor consumo de energia e matérias primas) com melhores condições de segurança. Para tanto, busca criar soluções da Engenharia de Automação para o desenvolvimento de produtos e projetos que atendam às necessidades da indústria por qualidade, redução de custos e padronização do produto final.

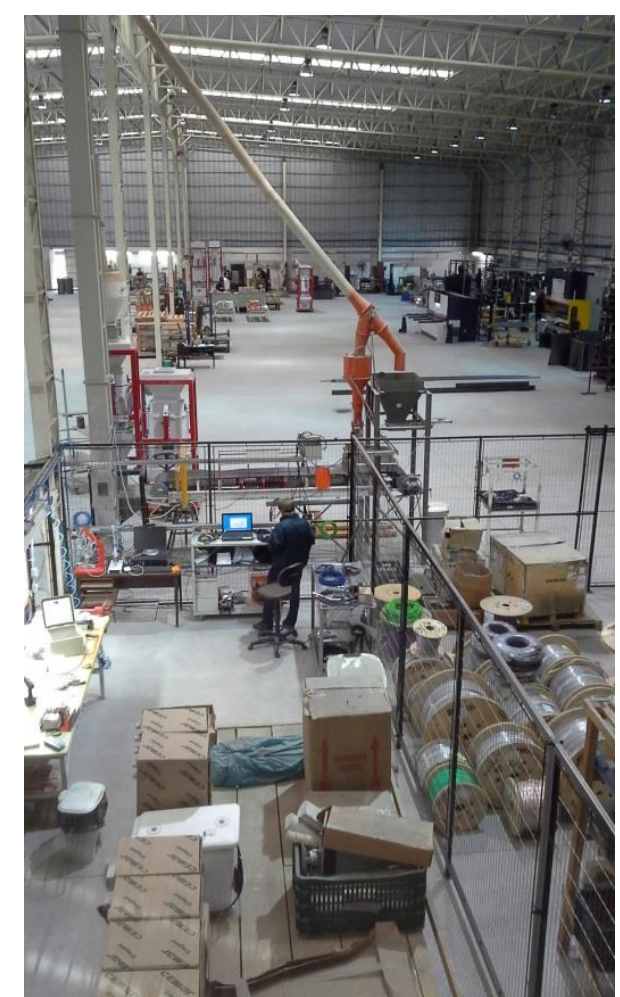

Figura 1 - Planta da Indústria de estudo - Acervo Pessoal. 

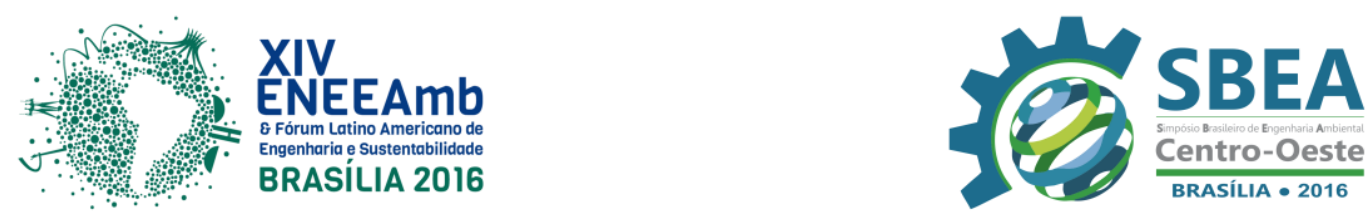

Para a realização deste trabalho foram realizadas visitas semanais, com a finalidade de observar o sistema de produção da empresa e entender seu funcionamento. Além disso, atentou-se às fontes geradoras de resíduos e ao gerenciamento dos mesmos no empreendimento (PIOTTO, 2003). Com isso, identificou-se e foram estabelecidos os diferentes setores da empresa, sendo que neste trabalho foram apresentados os setores de maior geração de resíduos, são eles mecânica, pintura e elétrica. Em seguida, os resíduos foram identificados e classificados de acordo com a Norma ABNT NBR 10004/04.

\section{RESULTADOS E DISCUSSÕES}

A empresa estudada apresenta diferentes fontes geradoras de resíduos, assim como diversas formas de geração. Como mencionado anteriormente a empresa foi dividida em três setores principais que possuem maior fonte de geração, são eles Mecânica, Elétrica e Pintura essa divisão foi estabelecida através da forma de trabalho e linha de produção. Ao caracterizar qualitativamente os resíduos percebeu-se claramente a diferença entre os mesmos, isso se deu através da percepção das diferentes matérias primas utilizadas e por consequência os diferentes resíduos sólidos resultantes. Para melhor visualização de cada setor foi delimitado na planta-baixa da empresa os setores em estudo, como está mostrado abaixo na Figura 2. O setor de pintura não está delimitado, pois se localiza do exterior da empresa.

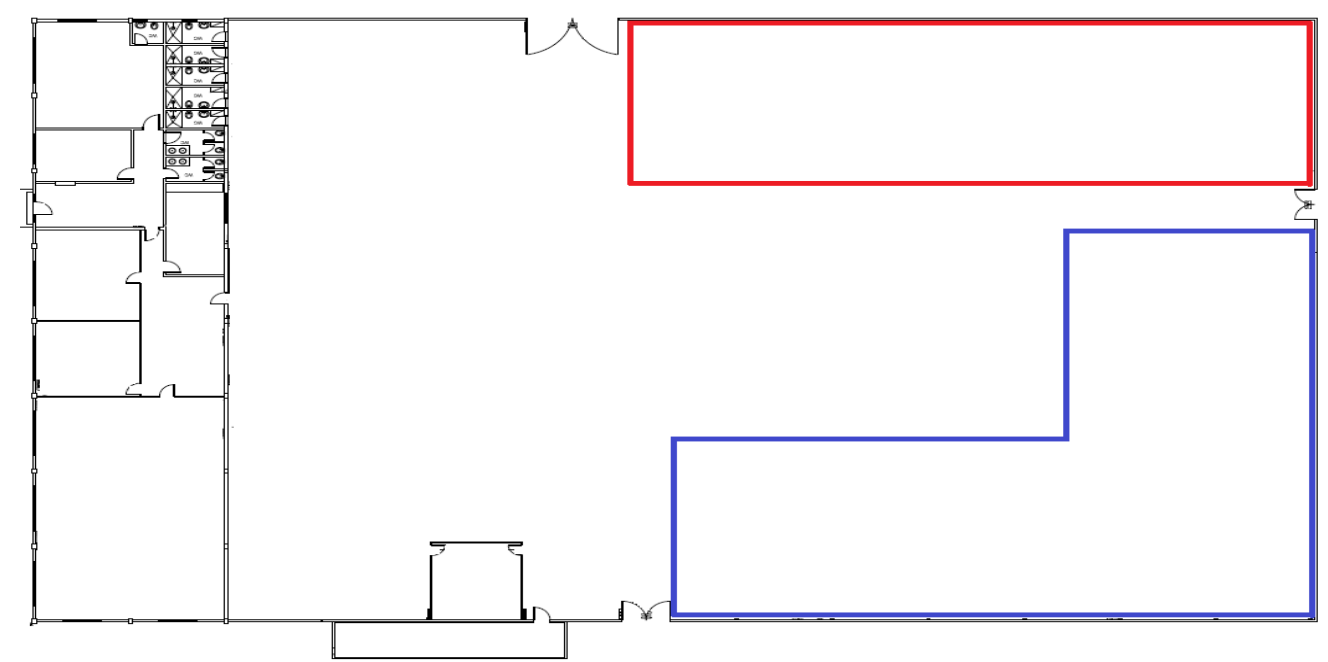

Figura 2 - Planta da Indústria de estudo, vermelho Setor Elétrico e azul Setor Mecânica - Arquivo pessoal.

O setor de Mecânica é incumbido pela confecção de equipamentos. A matéria-prima utilizada neste setor é teflon, aço 1020 e 1045, borracha, metalon, alumínio, latão, acrílico e tecnil, à vista disso são gerados grandes volumes de resíduos destes materiais, tanto na forma de sucata quanto limalhas e rebarbas. Também há geração de efluente neste setor, proveniente da limpeza de alguns equipamentos.

Após a identificação desse ponto gerador, foram caracterizados os resíduos gerados conforme a NBR 10004 (2004) como é explicitado na Tabela 1. Foram encontrados resíduos do tipo Classe I, como resíduos de limpeza de equipamentos, embalagens vazias contaminadas, disco de corte, resíduos de varrição, resíduos têxteis contaminados, entre outros e resíduos de Classe II como sucata, resíduos plásticos, papel e papelão, resíduos de borracha e outros. Devido à presença de resíduos de Classe I, torna-se ainda mais importante um gerenciamento de resíduos bem estruturado, conforme a legislação vigente. 

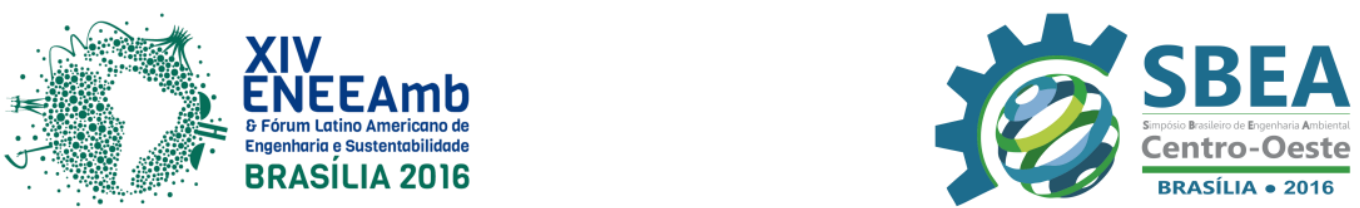

Tabela 1 -Identificação e classificação de resíduos sólidos gerados no setor de mecânica classificados de acordo com a Norma ABNT NBR 10004:2004.

\begin{tabular}{|l|c|l|l|}
\hline SETOR & ITEM & TIPO DE RESÍDUO & CLASSE \\
\hline \multirow{5}{*}{ Mecânica } & 1 & Resíduos de chapas (aço 1020 e 1045) & Classe I \\
\cline { 2 - 4 } & 2 & Disco de Lixadeira & Classe I \\
\cline { 2 - 4 } & 3 & Disco de Corte & Classe I \\
\cline { 2 - 4 } & 4 & $\begin{array}{l}\text { Resíduos de Varrição (limalha de aço 1020, } \\
1045, \text { borracha, tecnil e acrílico) }\end{array}$ & Classe I \\
\cline { 2 - 4 } & 5 & Embalagens Vazias Contaminadas & Classe I \\
\cline { 2 - 4 } & 6 & Resíduo de Limpeza de Equipamentos & Classe I \\
\cline { 2 - 4 } & 7 & Equipamentos EPIs contaminados & Classe I \\
\cline { 2 - 4 } & 9 & Resíduos Têxteis Contaminados (panos) & Classe I \\
\hline & 10 & $\begin{array}{l}\text { Resíduos Plásticos (embalagens, plástico bolha, } \\
\text { copos descartáveis) }\end{array}$ & Classe II A \\
\hline 11 & Aparas de Madeiramento II A \\
\cline { 2 - 4 } & 12 & Sucata de Metais não Ferrosos (alumínio) & Classe II A \\
\cline { 2 - 4 } & 13 & Sucata de Metais não Ferrosos (latão) & Classe II B \\
\cline { 2 - 4 } & 14 & Resíduo Plástico (acrílico) & Classe II B \\
\cline { 2 - 4 } & 15 & Resíduos Plásticos (Tecnil e acrílico) & Classe II B \\
\cline { 2 - 4 } & 16 & Resíduo de Borracha & Classe II B \\
\hline
\end{tabular}

Também foram analisados a armazenamento e destinação final dos resíduos gerados pelo objeto de pesquisa. A sucata (chapas de aço 1020 e 1045, metalon, latão e alumínio) gerada é acumulada na área externa da empresa sem nenhum tipo de proteção ou cuidado, ao atingir o volume de uma carga, esse resíduo é vendido para recicladores que buscam in loco.

As limalhas e rebarbas (teflon, aço 1020 e 1045, borracha, metalon, alumínio, latão, acrílico e tecnil), discos de lixadeira e corte, rebarbas de madeira e plástico oriundos da embalagem são encaminhados, via coleta urbana para aterro sanitário. Isto evidencia a falta de despreparo e/ou informação quanto ao descarte correto de resíduos de Classe I, pois previamente ao envio ao aterro é necessário haja um tratamento do resíduo. Equipamentos de proteção individual e resíduos têxteis, que na maioria das vezes estão contaminados com resíduos oleosos e tintura, vêm sendo armazenados em depósitos e mantidos dentro de caixas, aguardando uma destinação adequada. Em seu estudo sobre o gerenciamento de RS em uma empresa de usinagem no estado de São Paulo, Simião (2011) constatou uma maior geração de cavacos dentre os materiais não ferrosos, enquanto que no presente trabalho os retalhos de materiais não ferrosos na forma de sucata ou chapas possuíram maior ocorrência, isso pode se relacionar aos distintos produtos finais das empresas.

O Setor Elétrico é responsável pela fabricação de painéis elétricos sendo estes de pequeno ou grande. Para isso, as matérias-primas utilizadas são cobre, cabos de diversas funções, barramentos plástico e acrílico, canaletas de alumínio, borracha e também borne, contator, fusível, disjuntor de comando, fonte, relé e braçadeira plástica, esses últimos equipamentos que chegam prontos na empresa. Deste modo, grande parte dos resíduos gerados neste setor são embalagens plásticas, de papel e papelão.

A seguir, na Tabela 2, são identificados os resíduos encontrados no setor Elétrico que foram classificados conforme norma ABNT NBR 10004:2004. Pode-se observar a pequena geração de resíduos Classe I, mostrando que o setor apresenta pequeno potencial de geração 

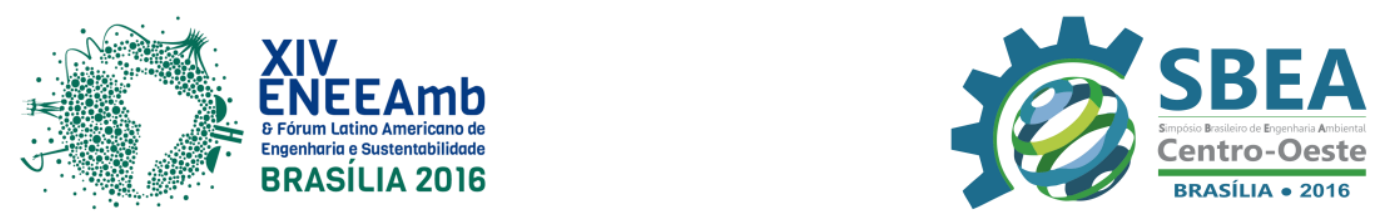

de resíduos perigosos, ao mesmo tempo possui uma grande geração de resíduos Classe II, sendo estes não perigosos, ou seja, possível potencial de encaminhamento para centrais de reciclagem.

Tabela 2 - Identificação e classificação de resíduos sólidos gerados no setor da elétrica classificados de acordo com a Norma ABNT NBR 10004:2004.

\begin{tabular}{|c|c|l|l|}
\hline SETOR & ITEM & TIPO RESÍDUO & CLASSE \\
\hline \multirow{5}{*}{ Elétrico } & 17 & Embalagens Vazias Contaminadas & Classe I \\
\cline { 2 - 4 } & 18 & Pontas de Eletrodo & Classe I \\
\cline { 2 - 4 } & 19 & Resíduo de Limpeza de Equipamentos & Classe I \\
\cline { 2 - 4 } & 20 & Aparas de Madeiramento & Classe II A \\
\cline { 2 - 4 } & 21 & Resíduo de Papel e Papelão & Classe II A \\
\cline { 2 - 4 } & 23 & Resíduos Plásticos (embalagens, plástico bolha, copos & \\
\cline { 2 - 4 } & 24 & Barramentos de Plástico & Classe II A \\
\cline { 2 - 4 } & 25 & Resíduo Plástico (acrílico) & Classe II B \\
\cline { 2 - 4 } & 26 & Resíduos de metais não ferrosos (Cobre) & Classe II B \\
\hline & 27 & Resíduos de Borracha & Classe II B \\
\hline & 28 & Cabos de Alimentação (exterior plástico, interior cobre) & Classe II B \\
\hline
\end{tabular}

Na montagem da estrutura são gerados resíduos de barramento de plástico, canaletas de alumínio e borracha. Grande quantidade de embalagens de plástico, papel e papelão, são destinados via coleta urbana para aterro sanitário. Há também um elevado consumo de cabos de alimentação, constituídos de cobre no interior e plástico no exterior, utilizados para a produção de painéis, podendo haver consumo de até 800 metros por painel, e com tempo de produção de aproximadamente um mês. Desta forma, a linha de produção gera resíduos de cabos de cobre de diferentes formas e tamanhos, não sendo possível a reutilização de todos. Devido ao comprimento necessário para a reutilização de fios de cobre, aqueles que possuem o comprimento mínimo necessário são armazenados e posteriormente reutilizados, os resíduos de tamanho inferior são dispostos em lixo comum e encaminhados via coleta urbana para aterro sanitário.

O Setor de Pintura é o único que não tem produção independente, devido ao seu trabalho com peças oriundas do setor de mecânica e elétrica. As peças de pequeno e médio porte são pintadas na empresa e, posteriormente, retornam ao seu setor de origem. Peças de porte maior tem sua pintura terceirizada e retornam somente para a etapa de montagem do produto final. O setor de pintura está localizado fora da planta industrial, em um container na área externa. Devido ao método de pintura utilizado, que consiste na aplicação de jatos de tinta diluídos em solvente, a deriva das partículas pulverizadas pode ocasionar impactos negativos no ambiente.

Durante as observações foi possível constatar o potencial alto de toxicidade em seu processo, visto que no jateamento é gerado fuligem de cobre e, durante a pintura, as partículas oriundas desse processo são lançadas no ambiente. Diante disso, todos os tipos de resíduos deste setor foram classificados como Classe I, como pode-se observar abaixo na Tabela 3. 

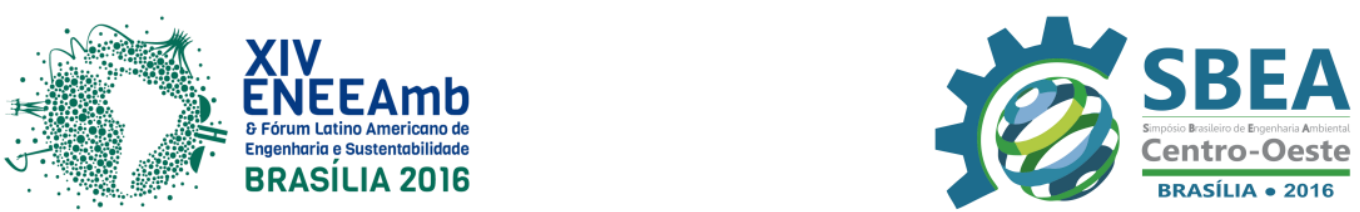

Tabela 3 - Identificação e classificação de resíduos sólidos gerados no setor de mecânica classificados de acordo com a Norma ABNT NBR 10004:2004.

\begin{tabular}{|c|c|l|c|}
\hline SETOR & ITEM & \multicolumn{1}{|c|}{ TIPO DE RESÍDUO } & CLASSE \\
\hline \multirow{5}{*}{ Pintura } & 29 & Borra de Tinta & Classe I \\
\cline { 2 - 4 } & 30 & Embalagens vazias contaminadas (tinta e solvente) & Classe I \\
\cline { 2 - 4 } & 31 & Resíduo de Limpeza de Equipamentos & Classe I \\
\cline { 2 - 4 } & 32 & Resíduos Têxteis Contaminados (panos) & Classe I \\
\cline { 2 - 4 } & 33 & Material Contaminado com Tinta & Classe I \\
\cline { 2 - 4 } & 34 & Equipamentos EPIs contaminados & Classe I \\
\cline { 2 - 4 } & 35 & Fuligem de Minério de Cobre & Classe I \\
\cline { 2 - 4 } & 36 & Resíduos de lixa contaminadas com tinta e solvente & Classe I \\
\cline { 2 - 4 } & 37 & Resíduos tóxicos gasosos de minério de cobre & Classe I \\
\hline
\end{tabular}

Os resíduos gerados nesse setor, em sua maioria, são embalagens vazias contaminadas, tais como latas de tinta e solvente, e ficam alojadas no exterior do container, em lugar abrigado, não possuindo uma destinação adequada, resultando num considerável passivo ambiental.

A limpeza das peças é feita através de jateamento com minério de cobre, em cabine adequada, possuindo um exaustor para que o efluente gasoso não entre no ambiente de trabalho. É gerado resíduo sólido de fuligem de cobre, sendo acumulado em um recipiente até sua plena capacidade de armazenamento, aguardando definição para sua correta destinação. As lixas de papel, pincel, resíduos têxteis, entre outros materiais contaminados com resíduo de tinta, apesar de serem resíduos perigosos, devido à sua alta toxicidade, são destinados à coleta urbana de resíduo comum e, posteriormente, encaminhados ao aterro sanitário. Schneider et al. (2003) abordam a dificuldade no gerenciamento de resíduos no setor de pintura pela geração de resíduos perigosos, oriundos da utilização de tintas e solventes. Assim, deve-se atentar ao manejo adequado desses resíduos a fim de evitar a contaminação ambiental. Neste estudo de caso, as empresas consultadas armazenavam seus resíduos em depósito em sua planta até sua disposição final em Aterros de Resíduos Industriais Perigosos, já no estudo em questão a empresa não possui descarte adequado e central de armazenamento dos resíduos gerados no setor de Pintura.

\section{CONSIDERAÇÕES FINAIS}

A partir da AVALIAÇÃO do sistema produtivo foi possível verificar pontos falhos na segregação, armazenamento e destinação final dos resíduos gerados. No intuito de adequar a gestão de resíduos da empresa, este diagnóstico serviu como base para a próxima etapa do trabalho, onde será desenvolvido e implementado um Plano de Gerenciamento dos Resíduos Sólidos (PGRS), o qual contemplará todas as etapas do manejo (geração, segregação, identificação, acondicionamento, coleta, armazenamento, tratamento e destinação final), assim como os princípios de não-geração, redução, reutilização, reciclagem. Além disso, os resíduos serão quantificados por unidade de tempo, a fim de projetar e dimensionar uma Central de Armazenamento de Resíduos na indústria. 


\section{REFERÊNCIAS}

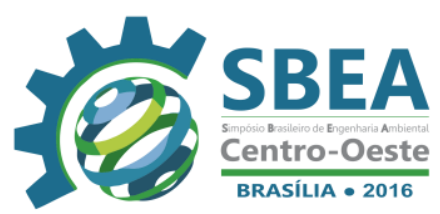

ASSOCIAÇÃO BRASILEIRA DE NORMAS TÉCNICAS. NBR 10004: Resíduos Sólidos Classificação. Rio de Janeiro, 2004.

BRASIL. Ministério do Meio Ambiente. Plano de gestão de resíduos sólidos: Versão pós Audiências e Consulta Pública para Conselhos Nacionais Brasília. Brasília, 2012.

BRASIL. Lei No 12.305 de 02 de Agosto de 2010. Política Nacional de Resíduos Sólidos. Brasília, 2010.

CORRÊA, E.K.; CORRÊA, L.B. Gestão de Resíduos Sólidos. Porto Alegre: Evangraf, 2012.

HEREDIA, B. Sociedade e economia do "agronegócio" no Brasil. Revista de Ciências Sociais, Vol. 25 nº74; outubro, 2010.

PEREIRA, D. A. Gestão e tratamento dos resíduos sólidos industriais na região sul do estado do Rio de Janeiro. Dissertação. Programa de Pós Graduação em Engenharia do Ambiente, FEUP. 2008.

MOURA, L. A. A. Qualidade e Gestão Ambiental - 4ªed. São Paulo: Juarez de Oliveira, 2004.

PIOTTO, Z. C. Eco-eficiência na indústria de celulose e papel - estudo de caso. Tese (Doutorado em Engenharia) - Escola Politécnica da Universidade de São Paulo;São Paulo, 2003. 379 p.

SCHNEIDER, V. E; HILlIG, E; PAVONI; E. T; RIZZON; M. R;FILHO; L. A. B. Gerenciamento ambiental na indústria moveleira - estudo de caso no município de Bento Gonçalves. In. XXIII Encontro Nacional de Engenharia de Produção, 2003, Ouro Preto. Anais XXIII Encontro Nacional de Engenharia de Produção. Ouro Preto.

SIMIÃO, J. Gerenciamento de Resíduos Sólidos Industriais em uma Empresa de Usinagem sobre o enfoque de Produção mais Limpa. Dissertação (Mestrado em Hidráulica e Saneamento). São Carlos: Universidade de São Paulo; 2011. 170p. 